\title{
Straight sinus: ultrastructural analysis aimed at surgical tumor resection
}

\author{
Marcelo Campos Moraes Amato, MD, ${ }^{1}$ Luis Fernando Tirapelli, MD, $\mathrm{PhD},{ }^{2}$ \\ Carlos Gilberto Carlotti Jr., MD, PhD, ${ }^{1}$ and Benedicto Oscar Colli, MD, PhD ${ }^{1}$
}

12Division of Neurosurgery and 2Division of Anatomy, Department of Surgery, Ribeirão Preto Medical School, University of São Paulo, Ribeirão Preto, São Paulo, Brazil

\begin{abstract}
OBJECTIVE Accurate knowledge of the anatomy of the straight sinus (SS) is relevant for surgical purposes. During one surgical procedure involving the removal of part of the SS wall, the authors observed that the venous blood flow was maintained in the SS, possibly through a vein-like structure within the dural sinus or dural multiple layers. This observation and its divergence from descriptions of the histological features of the SS walls motivated the present study. The authors aimed to investigate whether it is possible to dissect the SS walls while keeping the lumen intact, and to describe the histological and ultrastructural composition of the SS wall.
\end{abstract}

METHODS A total of 22 cadaveric specimens were used. The SS was divided into three portions: anterior, middle, and posterior. The characteristics of the SS walls were analyzed, and the feasibility of dissecting them while keeping the SS lumen intact was assessed. The thickness and the number of collagen fibers and other tissues in the SS walls were compared with the same variables in other venous sinuses. Masson's trichrome and Verhoeff's stains were used to assess collagen and elastic fibers, respectively. The data were analyzed using Zeiss image analysis software (KS400).

RESULTS A vein-like structure independent of the SS walls was found in at least one of the portions of the SS in 8 of 22 samples $(36.36 \%)$. The inferior wall could be delaminated in at least one portion in 21 of 22 samples $(95.45 \%)$, whereas the lateral walls could seldom be delaminated. The inferior wall of the SS was thicker $(p<0.05)$ and exhibited less collagen and greater amounts of other tissues-including elastic fibers, connective tissue, blood vessels, and nerve fibers $(p<0.05)$-compared with the lateral walls. Transmission electron microscopy revealed the presence of muscle fibers at a level deeper than that of the subendothelial connective tissue in the inferior wall of the SS, extending from its junction with the great cerebral vein to the confluence of sinuses.

CONCLUSIONS The presence of a structure within the SS that can maintain the venous blood flow despite the dural wall might be considered an anatomical variation. The greater thickness of the inferior wall of the SS compared with the lateral walls is mainly due to the presence of larger amounts of tissues other than collagen. Delamination of the inferior wall of the SS was mostly possible in its inferior wall, but an attempt to delaminate the lateral walls is not recommended. Ultrastructural assessment corroborated a recent report of the presence of muscle fibers in the inferior wall of the SS.

http://thejns.org/doi/abs/10.3171/2015.6.JNS15584

KEY WORDS straight sinus; dural sinuses; morphology; dura mater; neurosurgical implications; muscle fibers; anatomy

$\mathrm{T}$ HE straight sinus (SS) can be exposed to injury during surgical procedures involving the tentorium cerebelli (TC). ${ }^{25}$ For this reason, several neurosurgical and anatomical studies have focused on this anatomical region. Accurate knowledge of this area, which exhibits countless anatomical variations, could be useful for neurosurgeons who anticipate the need to resect a part of the SS during the removal of tumors adhering to the dura mater (DM) at the junction of the TC and the falx cerebri. ${ }^{7}$

Resection of lesions involving a dural sinus has been associated with a significant risk of cerebral venous infarction, ${ }^{17,19}$ which can be fatal. ${ }^{7,8}$ For that reason, portions of tumors adhering to a dural sinus are usually left in place, ${ }^{10,12}$ with consequent risk of relapse of disease. ${ }^{5,17}$ In

ABBREVIATIONS AnSS = anterior straight sinus; $C S=$ confluence of sinuses; $D M=$ dura mater; MidSS = middle straight sinus; $M T$ = Masson's trichrome; PoSS = posterior straight sinus; $S S=$ straight sinus; $S S S=$ superior sagittal sinus; $T C=$ tentorium cerebelli; $T E M=$ transmission electron microscopy; $T S=$ transverse sinus; VG = vein of Galen; VIH = Verhoeff's iron hematoxylin.

SUBMITTED March 16, 2015. ACCEPTED June 18, 2015.

INCLUDE WHEN CITING Published online January 8, 2016; DOI: 10.3171/2015.6.JNS15584. 
cases involving slow-growing tumors, the development of collateral vessels is believed to accommodate reverse flow without significant vascular congestion..$^{16,18}$ However, such speculation does not suffice as a safe indication for acute SS occlusion in surgical practice. ${ }^{16}$

The anatomical diversity of the tentorial sinuses, including the SS and its tributaries, has been well documented. . 1,4, $, 29,32,33$ Additionally, histological divergence has been found among these structures. ${ }^{11,15,25,26}$ Some studies have described spongy tissue embedded with collagen fibers, whereas others have not found that structure, but have found many elastic and few collagen fibers. ${ }^{11}$ Some studies have omitted mention of the presence-or have even reported an absence-of muscle fibers in the SS wall, ${ }^{13,15,20}$ whereas one study described their presence in the area close to the great cerebral vein of Galen (VG). ${ }^{11}$ No articles have commented on the possibility of dissecting or separating the layers composing the SS. During a surgical procedure conducted at the Clinical Hospital of Ribeirão Preto, University of São Paulo, we found that a part of the SS wall could be resected without compromising the venous flow, which was seemingly maintained by a vein within the sinus (Fig. 1).

If the sinus walls consist of various layers or a dural sinus contains a vein within its walls, resection of the external layers of the venous sinuses could be performed without impairment of the venous flow, thus improving surgical outcomes by permitting wider resections of neoplasms adhering to sinus walls-meningiomas in particu-
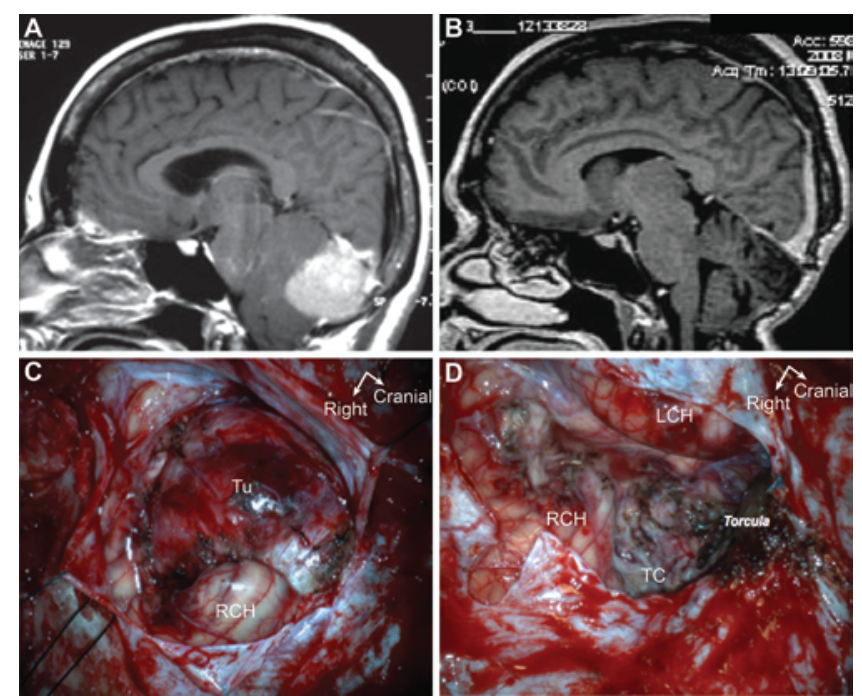

FIG. 1. Images of the case that motivated this study-a 51-year-old woman with a 1-month history of headache and dizziness; results of the neurological examination were normal. The operation was performed with the patient in a park bench position, and a craniotomy exposing the infratentorial compartment and the CS was completed. A and B: Sagittal T1-weighted MRI studies after Gd injection in a torcular meningioma attached to the TC and the SS; studies were obtained before and after total tumor removal. Note that the SS is patent after surgery (B) despite the fact that the tumor was attached to this sinus. C and D: Intraoperative photographs of the posterior fossa before and after removal of the infratentorial meningioma. Panel D shows the aspect of the CS (torcula) after resection of the inferior wall of the SS; the venous flow was not disturbed. $\mathrm{LCH}=$ left cerebellar hemisphere; $\mathrm{RCH}=$ right cerebellar hemisphere; $\mathrm{Tu}=$ tumor. lar. This still unresolved issue motivated the present study, the overall aim of which was to perform anatomical, histological, and ultrastructural analysis of the wall layers of the venous sinuses, particularly the SS, in a series of autopsy specimens, to increase knowledge of the histological composition of the SS and to raise the possibility of dissecting and separating its constituent layers.

\section{Methods}

A total of 22 anatomical specimens from necropsies performed at the Department of Pathology of the School of Medicine of Ribeirão Preto, University of São Paulo, were analyzed. The study was approved by the research ethics committee. The study included cadavers of individuals older than 18 years, of both sexes and any ethnicity; the exclusion criteria were as follows: death from a neurological cause, head injury, known disease affecting the sinuses, and lack of family consent. The relatives were asked to sign an informed consent document giving permission for study of the corpse and the use of resected samples for research purposes.

For macroscopic and microscopic assessment of the dural sinuses, an observational, descriptive study was performed. The relevant clinical data were collected from the individuals' clinical records, their relatives, and observation of the cadavers, including age, sex, ethnicity, weight, height, comorbidities, habits, and cause of death. Four corpses were female and 18 were male; their ages ranged from 20 to 81 years, with an average age of 59.7 years, a median of 66.5 years, and an SD of 17.9 years. Fourteen were white, 4 were of mixed race, 3 were black, and 1 was Asian.

Coronal incision, skull exposure, and craniotomy were performed, followed by removal of the brain; one specimen containing the DM from the posterior fossa and occipital region, TC, falx cerebri, falx cerebelli, transverse sinus (TS), SS, superior sagittal sinus (SSS), occipital sinus, and confluence of sinuses (CS) was carefully removed by dissecting and separating the internal cranial surface. The anatomical specimen containing the venous sinuses was prepared and sectioned, and the structures of interest were isolated. The areas assessed were the following: DM; anterior SS (AnSS); middle SS (MidSS); posterior SS (PoSS); superior sagittal sinus (SSS); right TS; and left TS. The SSS, right TS, and left TS samples were transversely sectioned $2 \mathrm{~cm}$ from the CS.

The final anatomical samples included the full extension of the SS from the tentorial incision to the CS. The size of the SS was assessed in 21 of the 22 specimens; in one specimen it could not be found. This measurement was obtained using millimeter rulers and measuring tape.

The SS samples were transversely sectioned at three points at different distances from the CS. To assess the AnSS, the section was performed close to the VG; to assess the PoSS, it was performed close to the CS; and to assess the MidSS, it was performed between the former two. The average distances of the transverse sections of the SS relative to the CS from the most anterior aspect to the most posterior aspect were $3.34,2.06$, and $1 \mathrm{~cm}$, respectively. All measurements were obtained by a single examiner us- 
ing one-decimal-point precision. All measurements were performed at least twice for the purpose of systematic checking.

Following transverse sectioning of all sinuses, the samples were prepared for assessment under a light microscope; the immediately adjacent sections were assessed macroscopically and photographed.

\section{Light Microscopy Assessment}

Following sectioning and reduction, the DM and venous sinus samples were prepared for microscopic assessment. For that purpose, H \& E stain was used, as were stains specific for collagen (Masson's trichrome [MT] and Sirius red) and for other tissues, including elastic fibers (Verhoeff's iron hematoxylin [VIH]).

For the assessment of morphological characteristics and thickness, the slides were analyzed and documented using a Zeiss Axioskop 2 plus microscope (Carl Zeiss Microscopy) at $\times 50, \times 100, \times 400$, and $\times 1000$ magnification. Images were acquired using a camera (Axio Cam $\mathrm{Hrc}$ ) coupled to the microscope and were stored using Axio Vision software, version 4.6. That software was used to assess the following parameters in the investigated specimens: number of layers, presence of septa, presence of endothelium, presence of vacuoles, and thickness (Fig. 2E). To assess the number of collagen fibers and other tissues, including elastic fibers, the same system was used. The data were processed using KS400 software (Fig. 2A-D).

The possibility of SS wall delamination was assessed based on macroscopic and microscopic characteristics, and the walls were classified into 4 categories. An attempt was made to separate the wall layers into fresh sections without magnification (Fig. 3). No differences were found in the wetness of the specimens. The cadavers were dissected 6.6 hours after death, on average. Four specimens were assessed 10-14 hours after death, and no deterioration was found in the structures; these specimens were also classified according to the above-mentioned categories. During this stage, subjective classification sought to facilitate understanding of the assessment that would be performed later, as well as to find evidence supporting the surgical application of the study results. The samples were classified as follows. Nondissectible: the wall could not be delaminated, and microscopy revealed one single layer in the sinus wall or two closely juxtaposed layers. Easy: well-separated layers were observed under light microscopy, and/or delamination was possible. Hard: closely juxtaposed layers were observed under light microscopy, and/or delamination was difficult. Partial: well-separated layers were observed in one place, but layers were closely juxtaposed in another.

\section{Transmission Electron Microscopy Assessment}

One small sample from a transverse section of each of the 21 SSs was chosen and analyzed using transmission electron microscopy (TEM). The structures were selected for analysis as follows: AnSS inferior wall, 4.76\% (1/21); MidSS inferior wall, $61.90 \%$ (13/21); PoSS inferior wall, $23.80 \%(5 / 21)$; and septum, $9.52 \%(2 / 21)$.

For the purpose of ultrastructural assessment, samples
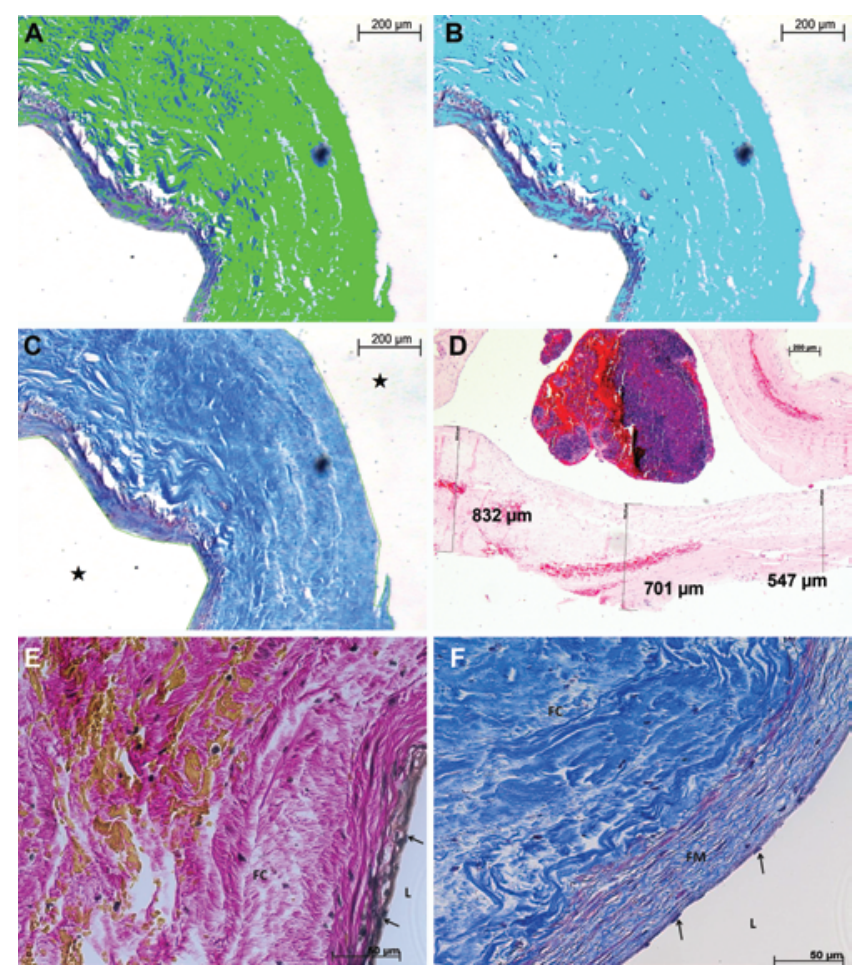

FIG. 2. A-C: Photomicrographs of a transverse histological section of the AnSS stained to permit measurement of the number of collagen fibers. A: Photomicrograph obtained after automatic pixel labeling of the collagen fibers in the lateral wall of the AnSS by KS400 software. B: Photomicrograph obtained following correction, including pixel addition and deletion. C: Exclusion of the areas that do not belong to the wall (stars) and appearance of the wall without pixel labeling. These steps were repeated in two to five fields per structure, according to their size, in such a manner as to encompass the full structure. When the labeling of all fields was complete, the software calculated the percentage of fibers in the entire field. A similar process was performed after VIH staining to measure the amounts of other tissues, including elastic fibers. D: Photomicrograph of a transverse histological section of the PoSS. The inferior wall was measured at three points, and the thickness of the inferior wall of the PoSS was calculated from the arithmetic mean of the three measurements. E: Photomicrograph of the inferior wall of the middle portion of the SS, with the sinus lumen and the presence of subendothelial elastic fibers (arrows) stained black and a large number of collagen fibers stained red filling the connective tissue layer. F: Photomicrograph of the inferior wall of the anterior portion of the SS and identification of its layers starting from the lumen: nuclei of the endothelial cells (arrows), muscle fibers in the smooth-muscle layer (red) and the external connective tissue layer containing collagen fibers stained blue. Stains: MT (A, B, C, F); H \& E (D); VIH (E). FC = collagen fibers; FM = muscle fibers; $L=$ lumen.

of the venous sinuses were immersed in a $2.5 \%$ glutaraldehyde fixation solution in $0.1 \mathrm{M}$ phosphate buffer, $\mathrm{pH} 7.4$, for 4 hours at $4^{\circ} \mathrm{C}$ and then washed with $0.1 \mathrm{M}$ phosphate buffer for 24 hours. The samples were then postfixed with $2 \%$ osmium tetroxide in $0.2 \mathrm{M}$ phosphate buffer for 4 hours at $4^{\circ} \mathrm{C}$, washed with $0.1 \mathrm{M}$ phosphate buffer for 24 hours, and then dehydrated in a series of increasing acetone concentrations (30\%-100\%). The samples were embedded in araldite resin for inclusion; following resin polymerization, the blocks were cut into $0.5-\mu \mathrm{m}$-thick sections to facilitate selection of the best areas, which were cut into $600-\AA \AA-$ thick slices using a diamond knife. 


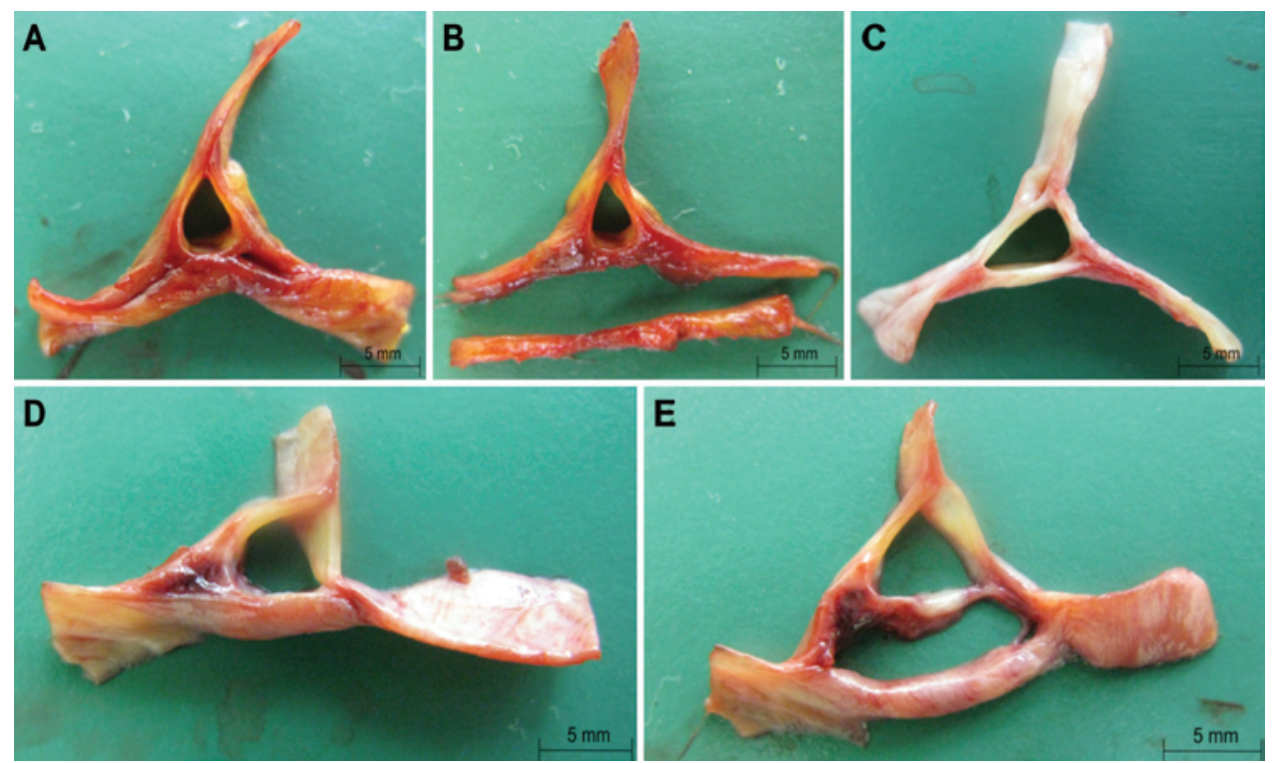

FIG. 3. Photographs of transverse sections of the PoSS of three different specimens exhibiting various degrees of dissection difficulty. A and B: Before and after easy dissection of the PoSS inferior wall. C: Nondissectible PoSS. D and E: Before and after difficult dissection of the PoSS inferior wall.

The slices were mounted on copper grids, contrasted with uranyl acetate, and examined under a Philips EM 208 transmission electron microscope.

\section{Statistical Methods}

The categorical data, including numbers of patients and percentages, were summarized using descriptive statistics. The numerical data were summarized as means, SDs, medians, maximums, and minimums. The normality of the data was investigated using the Kolmogorov-Smirnov test. Because the distributions were assumed to be normal, numerical variables corresponding to the same individual were compared using the paired t-test or by ANOVA when more than two related variables were assessed. The independent-samples t-test was used to compare one numerical variable between different categories. The level of significance was $\mathrm{p}<0.05$. The statistical analysis was performed using Minitab software, version 16.1.

\section{Results}

\section{Morphological Study of the SS Light Microscopy}

The reference point for the histological description of the SS was its lumen (Fig. 2F), which exhibited an endothelial lining with patent cell nuclei (Fig. 2H). The next level corresponded to a thin layer of subendothelial connective tissue containing collagen and elastic fibers (Fig. $2 \mathrm{~F}-\mathrm{H})$. Deeper in, histological staining revealed the presence of a muscle layer consisting of smooth-muscle fibers with elongated nuclei (Fig. 2H), mostly arranged in circles. This muscle layer was not patent or characteristic in any of the areas of the assessed samples. Finally, the outermost level was represented by a thick layer of connective tissue consisting mostly of collagen fibers (Fig. $2 \mathrm{~F}-\mathrm{H}$ ).

\section{Presence of a Vein-Like Structure Within the SS}

Macroscopic and microscopic studies of the SS transverse sections revealed the presence of a vein-like structure in at least one portion of the SS in 8 of the 22 analyzed specimens $(36.36 \%)$ (Table 1$)$.

\section{Number of Patent Layers in the SS Wall}

Macroscopic and microscopic studies of the SS transverse sections revealed the presence of two layers in at least one portion of the inferior wall of the SS in 20 of 22 samples (90.90\%), in two portions of the wall in 18 of 22 samples $(81.81 \%)$, and in all three portions of the wall in 14 of 22 samples $(63.63 \%)$ (Table 1$)$.

\section{Presence of Septa in the SS}

Macroscopic and microscopic study of the SS transverse sections revealed the presence of a septum in at least one portion of the SS in 9 of 22 samples (40.90\%). The AnSS exhibited a septum in 6 of 21 samples (28.57\%), the MidSS in 3 of 21 samples (14.28\%), and the PoSS in 4 of 22 samples (18.18\%). The SS exhibited a septum across its full extent only in Specimen 17 (Table 1).

\section{Difficulty of Dissecting and Separating the SS Walls}

Macroscopic analysis revealed that the SS inferior wall was the thickest wall in most of the cases. Indeed, in the cases with vein-like structures within the SS, the lateral walls could seldom and only partially be delaminated at their angle with the inferior wall. For this reason, only the possibility of delaminating the inferior wall was assessed in the present study. Such dissection was possible in at least one portion of the SS in 21 of 22 specimens. Delamination was fully impossible in one specimen (No. 6) in which the SS was blind-ended; in this specimen, only the posterior portion of the SS, together with the CS, could be removed (Table 1). 


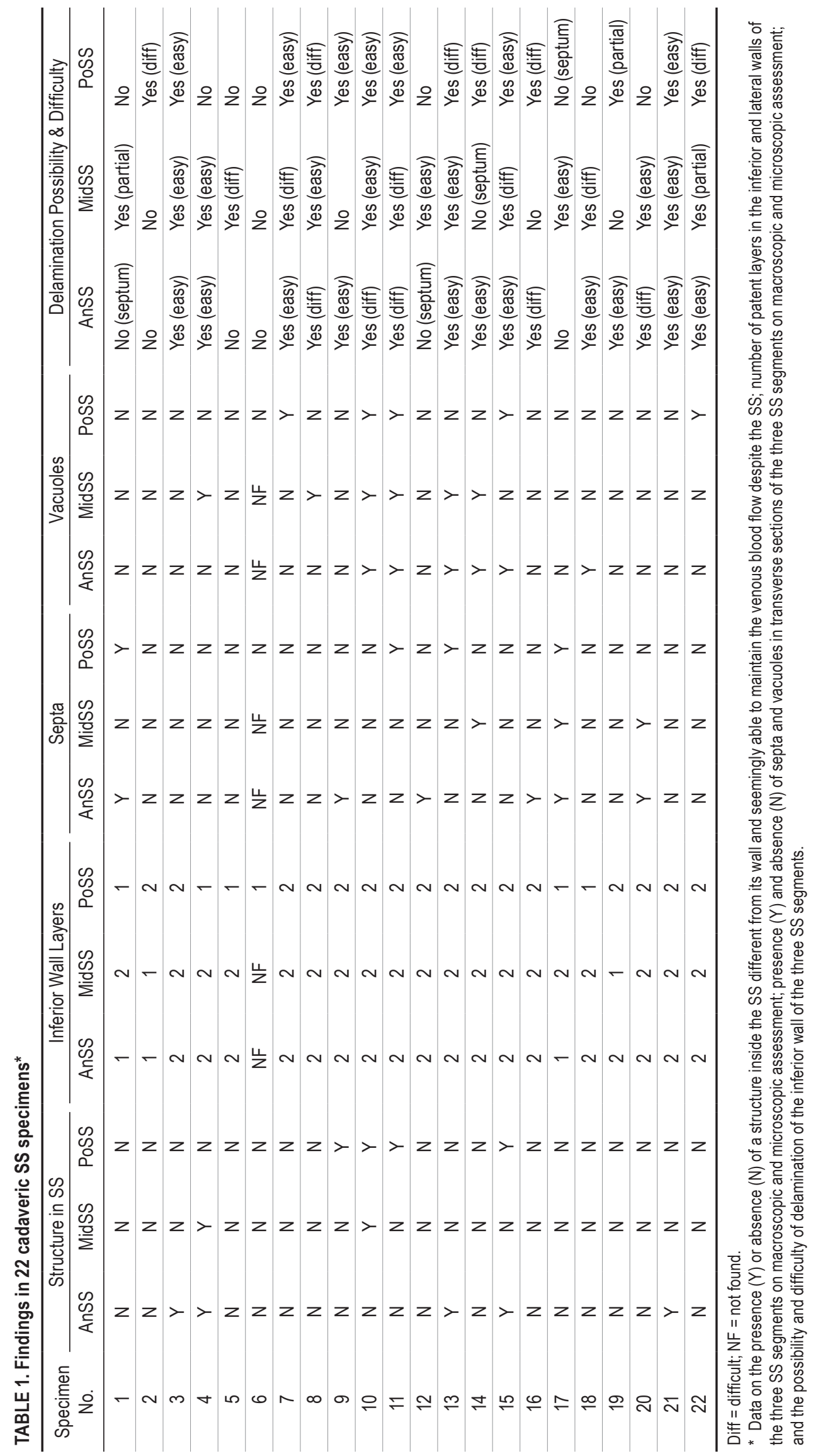


Comparison of the results obtained by light microscopy showed that when only one layer was detected by this method, it could not be delaminated. The occurrence of two nonseparable layers manifested as closely juxtaposed layers, with no space between them and containing collagen fibers oriented in different directions.

The presence of a septum exerted an influence on delamination: spontaneous separation of the walls notwithstanding, the samples with septa exhibited two endothelium-lined lumens, whereas the remainder of the wall was thinner and could not be delaminated. For instance, the inferior wall in Specimen 12 exhibited a septum and could not be delaminated beyond it. In Specimen 14, although the septum patently divided the dural channel lumen into two sections, the wall was thinner and could not be separated. In Specimen 16, dissection was difficult and possible only up to the septum; on one side of the septum, the wall was extremely thin and could not be delaminated. The septum in the MidSS of Specimen 17 allowed for layer separation; however, dissection was impossible in the PoSS because it exhibited a single layer. In Specimen 1, the AnSS could not be delaminated because it exhibited a single layer; partial separation could be achieved in the MidSS, but delamination was not possible in the PoSS because the septum was connected to the posterior portion of the CS rather than to the walls of the PoSS (Table 1).

\section{Presence of Endothelium}

Endothelium was identified in all the assessed samples. In the samples with septa, the dural sinus exhibited two lumens, both lined by endothelium. The samples that exhibited a vein-like structure within the sinus, despite the patent separation between the dural layer and the "vein," had no endothelium between these two structures.

\section{Presence of Vacuoles}

Microscopic study of the SS transverse sections revealed the presence of vacuoles in the inferior wall of at least one portion of the SS in 10 of 22 samples $(45.45 \%)$, in two portions in 5 of 22 samples (22.72\%), and in all three portions in 2 of 22 samples (9.09\%) (Table 1). We considered the presence of vacuoles in only the inferior wall of the SS because they seemed to facilitate its delamination. However, some of the samples exhibited vacuoles also in the lateral walls, which nonetheless were nondissectible (e.g., Specimen 15, MidSS).

A total of 12 SS portions exhibited vacuoles and were easy to dissect (Specimens 4, MidSS; 7, PoSS; 8, MidSS; 10, MidSS; 10, PoSS; 11, PoSS; 13, AnSS; 13, MidSS; 14 , AnSS; 15, AnSS; 15, PoSS; and 18, AnSS). Four portions exhibited vacuoles but were difficult to dissect (Specimens 10, AnSS; 11, SS; 11, MidSS; and 22, PoSS), and only one portion exhibited vacuoles but could not be dissected (Specimen 14, MidSS).

\section{Association Between the Thickness and Composition of the DM and the Venous Sinuses in the Posterior Fossa}

\section{Comparison of the SS Inferior and Lateral Walls}

Statistical analysis of the data on the thicknesses and percentages of collagen fibers and other tissues revealed a statistically significant difference $(\mathrm{p}<0.05)$ between the inferior and lateral walls of each SS portion (Table 2 and Fig. 4). The inferior wall was the thickest in all three portions, exhibiting the lowest percentage of collagen fibers and the largest percentage of other tissues, including elastic fibers, connective tissue, blood vessels, and nerve fibers.

\section{Comparison of the Inferior Wall Among the SS Portions}

The thicknesses and percentages of collagen and elastic fibers in the inferior wall did not differ among the three SS portions $(p>0.05)$. In all three portions of the SS, the inferior wall was similar in thickness, percentage of collagen, and percentage of other tissues.

\section{Comparison of the PoSS Portion to Other Venous Sinuses in the Posterior Fossa}

The thickness, percentage of collagen fibers, and percentage of other tissues were compared between the PoSS and other venous sinuses (Fig. 5A-G and Table 3). No differences were found in thickness or percentage of other tissues between the PoSS and SSS, whereas the remainder of the comparisons exhibited significant differences $(\mathrm{p}$ $<0.05$ ). The PoSS wall was thicker than the walls of the right TS and left TS, the percentage of collagen fibers was lower in the PoSS than in the SSS, right TS, and left TS, and the percentage of other tissues was higher in the PoSS than in the right TS and left TS.

\section{Correlation Between Numbers of Collagen Fibers and Other Tissues and DM and Inferior SS Wall Thicknesses}

No correlations between the numbers of collagen fibers and other tissues and the DM and inferior SS wall thickness were found $(\mathrm{p}>0.50)$.

\section{Analysis of SS Portions by TEM}

Ultrastructural analysis of the inferior wall of the SS by TEM showed that the three portions (anterior, middle, and posterior) were histologically similar. The SS exhibited a thin internal endothelial lining in which elongated nuclei were frequently observed (Fig. 6A). The endothelium was in direct contact with the SS lumen, which was filled with venous blood. A thin layer of connective tissue consisting of collagen and elastic fibers was observed beneath the endothelium.

The SS wall included one layer consisting of fusiform smooth-muscle fibers with occasional cytoplasmic extensions. This layer was deeper than the subendothelial connective tissue, and the muscle fibers were arranged in concentric circles; on the electron micrographs they appeared as elongated fibers (Fig. 6A-C). Additionally, some longitudinal fibers were observed intertwined with the circular fibers.

On histological analysis, the cell membrane of the muscle fibers (sarcolemma) was clearly patent and exhibited dense bodies of various sizes and shapes all along its internal surface (Fig. 6B). The main characteristic of the sarcoplasm was the presence of longitudinal myofilaments, with dense fusiform areas and oval bodies appearing as areas of greater electron density between myofilaments. The myofilaments represented most of the sarcoplasm, which also contained vesicles or particles of lipids and glycogen of various sizes and densities (Fig. 6B), as well 
TABLE 2. Comparison of thickness, percentage of collagen fibers, and percentage of other tissues between the inferior and lateral walls of each SS portion

\begin{tabular}{|c|c|c|c|c|c|c|c|}
\hline Characteristic & SS Segment & No. of Specimens* & Mean & SD & Median & t Value & $\mathrm{p}$ Value \\
\hline \multirow[t]{9}{*}{ Thickness } & Inferior AnSS & \multirow[t]{3}{*}{20} & 1150.4 & 375 & 83.9 & 7.29 & $<0.001$ \\
\hline & Lateral AnSS & & 553.5 & 163.2 & 36.5 & & \\
\hline & Difference & & 597 & 366.3 & 81.9 & & \\
\hline & Inferior MidSS & \multirow[t]{3}{*}{21} & 944.7 & 383.5 & 83.7 & 5.14 & $<0.001$ \\
\hline & Lateral MidSS & & 550.1 & 168.4 & 36.7 & & \\
\hline & Difference & & 394.6 & 351.6 & 76.7 & & \\
\hline & Inferior PoSS & \multirow[t]{3}{*}{21} & 1071.3 & 282 & 61.5 & 7.47 & $<0.001$ \\
\hline & Lateral PoSS & & 559.2 & 204 & 44.5 & & \\
\hline & Difference & & 512.1 & 314 & 68.5 & & \\
\hline \multirow[t]{9}{*}{ Collagen fibers } & Inferior AnSS & \multirow[t]{3}{*}{21} & 0.4270 & 0.1057 & 0.0231 & -6.48 & $<0.001$ \\
\hline & Lateral AnSS & & 0.5433 & 0.0915 & 0.0200 & & \\
\hline & Difference & & -0.1164 & 0.0823 & 0.0180 & & \\
\hline & Inferior MidSS & \multirow[t]{3}{*}{21} & 0.4136 & 0.1062 & 0.0232 & -4.07 & 0.001 \\
\hline & Lateral MidSS & & 0.5078 & 0.0824 & 0.0180 & & \\
\hline & Difference & & -0.0942 & 0.1060 & 0.0231 & & \\
\hline & Inferior PoSS & \multirow[t]{3}{*}{20} & 0.4290 & 0.1042 & 0.0233 & -3.46 & 0.003 \\
\hline & Lateral PoSS & & 0.5142 & 0.0869 & 0.0194 & & \\
\hline & Difference & & -0.0852 & 0.1102 & 0.0246 & & \\
\hline \multirow[t]{9}{*}{ Other tissues $†$} & Inferior AnSS & \multirow[t]{3}{*}{21} & 0.0610 & 0.0370 & 0.0080 & 6.12 & $<0.001$ \\
\hline & Lateral AnSS & & 0.0246 & 0.0227 & 0.0049 & & \\
\hline & Difference & & 0.0363 & 0.0272 & 0.0059 & & \\
\hline & Inferior MidSS & \multirow[t]{3}{*}{21} & 0.0588 & 0.0336 & 0.0073 & 5.11 & $<0.001$ \\
\hline & Lateral MidSS & & 0.0195 & 0.0241 & 0.0052 & & \\
\hline & Difference & & 0.0393 & 0.0352 & 0.0076 & & \\
\hline & Inferior PoSS & \multirow[t]{3}{*}{21} & 0.0044 & 0.0272 & 0.0059 & 4.05 & 0.001 \\
\hline & Lateral PoSS & & 0.0211 & 0.0204 & 0.0044 & & \\
\hline & Difference & & 0.0236 & 0.0267 & 0.0058 & & \\
\hline
\end{tabular}

* The PoSS of Specimen 1 was absent, possibly due to anatomical variations and anastomotic channels within the tentorium. After preparation of the AnSS of Specimen 2, the laminae were found to be of poor quality and the authors preferred to exclude only this segment in the data analysis.

$†$ Elastic fibers, connective tissue, blood vessels, and nerve fibers.

as mostly round or rod-shaped mitochondria (Fig. 6A). The organelles mostly occupied the central space close to the nuclear pole and proximal to the sarcolemma or were scattered among the myofilaments. The muscle fibers, as a rule, exhibited one large central nucleus with an elliptical shape, with lightly packed chromatin (euchromatin) and heterochromatin only in its peripheral area. In some cells the nucleus exhibited a typical interphase appearance (Fig. $6 \mathrm{~A}$ and $\mathrm{C}$ ).

The outermost level of the muscle fibers consisted of a thick layer of connective tissue, almost fully consisting of longitudinal and transverse collagen fibers (Fig. 6D). Thin bundles of high-electron-density elastic fibers, as well as fibroblasts characteristically exhibiting elongated nuclei and cytoplasm, were observed among the collagen fibers.

\section{Discussion}

\section{Morphological Findings}

In the course of the formation of the SS, as the brain hemispheres increase in size, the DM mesenchymal tissue is compressed between them above the mesencephalon and rhombencephalon, forming folds. ${ }^{34}$ Together with the formation of these folds, the anterior and posterior plexuses merge to form the various venous sinuses that are contained within them (Fig. 7A-D). Due to individual differences in the mode of fusion, countless anomalies occur in the resulting sinuses. $7,32,34$ The variations in the SS include its trajectory, position in the TC, channel duplication, endings, and other characteristics. ${ }^{31,32}$ The presence of a vein-like structure within the SS might correspond to one such variation and might be detected during surgical procedures. We found a vein-like structure in at least one portion of the SS in 8 of 22 samples (36.36\%), suggesting that this anatomical variation is relevant and thus should be known by neurosurgeons.

The DM has two layers, an external and an internal layer, which are intimately united in adults. ${ }^{2,35}$ The external layer, also known as the periosteal DM, lines the internal surface of the calvaria, whereas the internal layer, known 
A

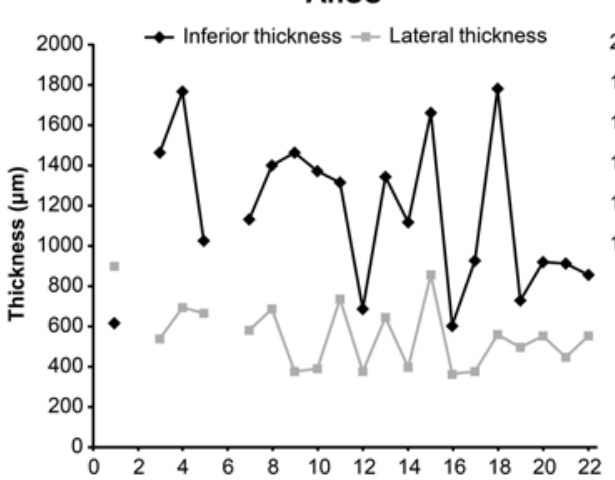

D

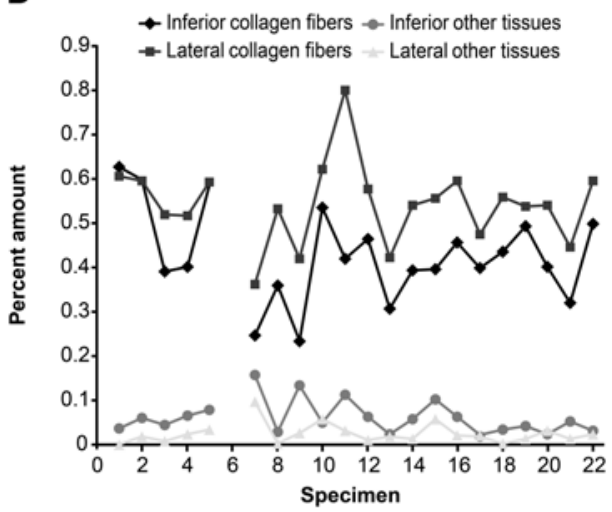

B

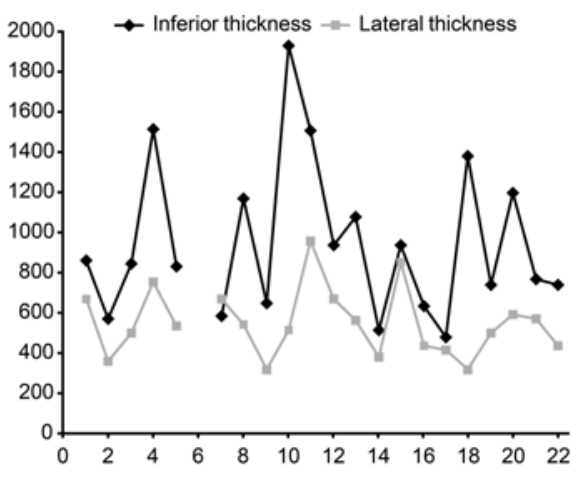

E

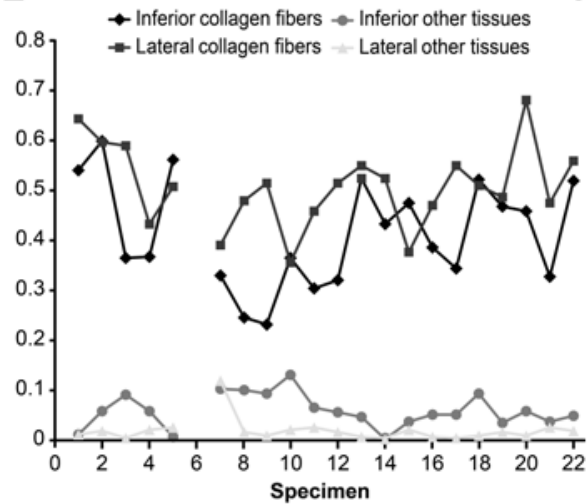

C Poss

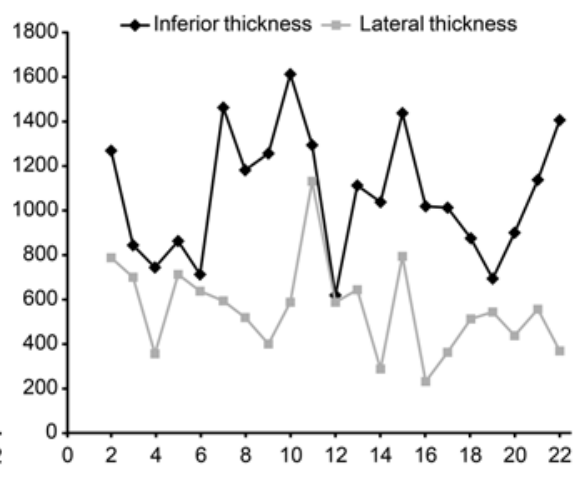

$\mathbf{F}$

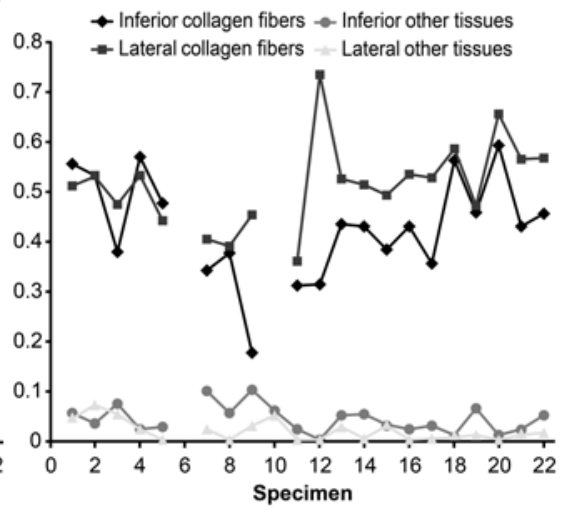

FIG. 4. Graphs showing comparisons of the thickness of the inferior and lateral walls of the AnSS (A), MidSS (B), and PoSS (C) (significant difference: $p<0.05)$. Graphs showing comparisons of the percentages of collagen fibers and other tissues (elastic fibers, connective tissue, blood vessels, and nerve fibers) of the inferior and lateral walls of the AnSS (D), MidSS (E), and PoSS (F) (significant difference: $p<0.05$ ).

as the meningeal DM, is in contact with the brain..$^{35}$ In some brain areas, the internal layer separates from the external layer to form folds that project inside the brain, where, in addition to containing venous sinuses, they form septa. ${ }^{2,21,35}$ Thus, a single DM layer forms the walls of the main venous sinuses. Nevertheless, some embryological studies have shown that the components of the perineural vascular territory, which is the origin of the venous sinuses, develop while embedded within the embryonic meningeal compartment, more specifically within the external stratum or dural system. ${ }^{23,24}$ This development might account for the double layer found in the walls of some sinuses. Indeed, we found that the SS inferior walls in which dissection was possible exhibited two patent layers. Independent of the possibility of dissection, light microscopy revealed the presence of two layers in the inferior wall of at least one SS portion in 20 of 22 samples (90.90\%), in two portions in 18 of 22 samples (81.81\%), and in all three portions in 14 of 22 samples (63.63\%).

The observed duplication of the SS walls might be explained by the presence of a vein-like structure within them. Alternatively, the dural layers that separate and form folds might reunite at the meeting point between the falx cerebri and the TC, resulting in a double layer (Fig. 7 inset). If the latter were the case, the SS would be formed exclusively by the meningeal DM and would thus differ from the uncovered sinuses, the most superficial wall of which corresponds to the external layer of the DM. That relationship might partially explain the observed morphological differences between the SS and the remainder of the analyzed sinuses.

The average size of the SS was $4.28 \mathrm{~cm}$, varying from 3.0 to $5.1 \mathrm{~cm}$. These values are lower than those reported by Saxena et al. $(5.0 \mathrm{~cm}$, range $4.0-6.9 \mathrm{~cm})$.

Several authors have found double and even triple SS. 7,18,19,22 Browder et al. assessed 131 specimens and found no two identical venous channel patterns in the TC, whereas duplication of the main SS trunk occurred in all of its three (anterior, middle, or posterior) portions. ${ }^{7}$ In our study, the presence of a septum in at least one SS portion was found in 9 of 22 samples (40.90\%), alternatively located in any portion. A septum was found in the anterior portion in 6 of 21 samples (28.57\%), in the middle portion in 3 of 21 samples (14.28\%), and in the posterior portion in 4 of 22 samples (18.18\%). A septum was present along the entire SS extension in only one specimen, and no cases exhibited full SS duplication.

Even by macroscopic assessment, the thickness of the SS inferior wall was greater than that of the lateral walls, which allowed for delamination of at least one portion, even if difficult, in 21 of 22 samples. This finding indicates why a part of the SS wall could be dissected during a surgical procedure performed in our center while keeping the venous flow patent, although the venous flow was not 

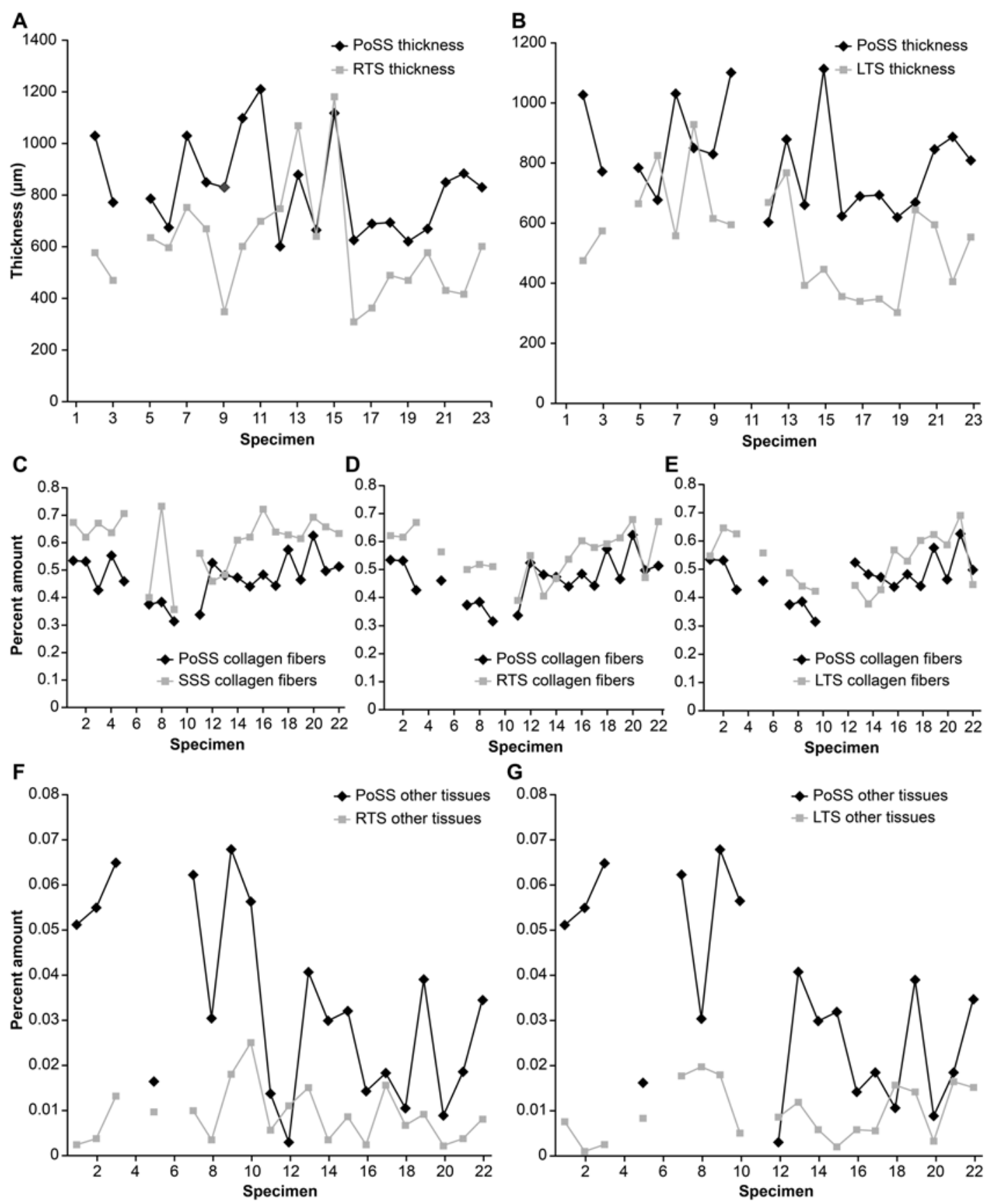

G

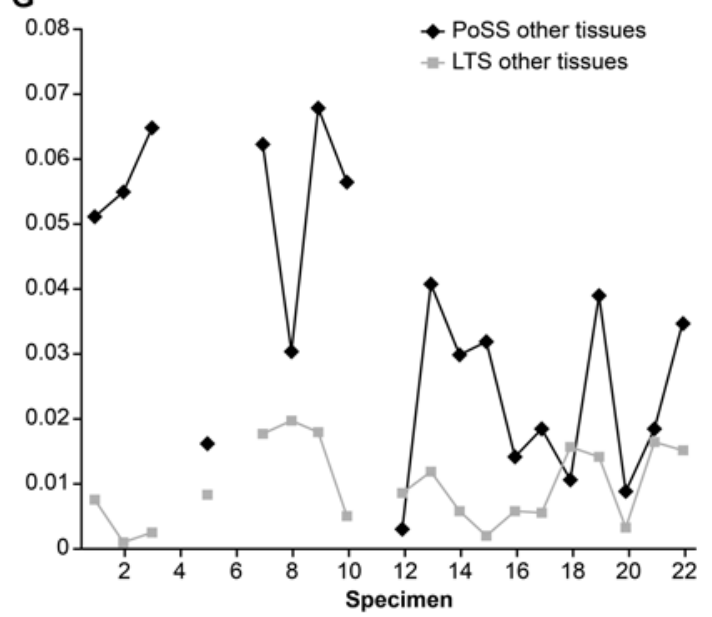

FIG. 5. Graphs showing comparisons of the average thickness of the inferior and lateral walls in the PoSS and the right TS (RTS) (A) and in the left TS (LTS) (B) (significant difference: $p<0.05$ ). Graphs showing comparisons of the percentage of collagen fibers in the PoSS, SSS (C), right TS (D), and left TS $(E)$ (significant difference: $p<0.05)$. Graphs showing comparisons of the percentage of other tissues in the PoSS, right TS (F), and left TS (G) (significant difference: $p<0.05$ ).

due to the presence of a vein within the sinus but to the occurrence of a double-layered wall. In one specimen of the present sample, the sinus exhibited a blind end and no SS portion could be dissected; only the posterior portion of this specimen, together with the CS, could be removed for analysis. The absence of an SS is thus a further anatomical variation that might occur in this area. Ryu described an absence of or a rudimentary SS associated with persistence of the falcine venous sinus, which is considered a rare variation in the venous pathway between the dural layers of the falx cerebri that is present in $2.1 \%$ of cases. ${ }^{30}$

The anomalies occurring in the SS might extend to the CS through the septa, which are residues of the dural wall formed in the course of development of the sinuses of the posterior fossa. ${ }^{28}$ The presence of such septa might direct the venous flow in various directions toward and away from the CS. ${ }^{28}$ The fact that septa were found in three $(13.63 \%)$ specimens in the present series led us to believe 
TABLE 3. Comparison of the posterior SS portion to the remainder of venous sinuses in the posterior fossa in thickness, percentage of collagen fibers, and percentage of other tissues

\begin{tabular}{|c|c|c|c|c|c|c|c|}
\hline Characteristic & Sinus & No. of Specimens* & Mean & SD & Median & t Value & $p$ Value \\
\hline \multirow[t]{9}{*}{ Thickness } & PoSs & 21 & 815.3 & 189.6 & 41.4 & 0.60 & 0.554 \\
\hline & SSS & & 765.7 & 310.7 & 67.8 & & \\
\hline & Difference & & 49.6 & 377.6 & 82.4 & & \\
\hline & Poss & 20 & 828.4 & 184.4 & 41.2 & 4.68 & $<0.001$ \\
\hline & Rt TS & & 601.9 & 221.7 & 49.6 & & \\
\hline & Difference & & 226.5 & 216.3 & 48.4 & & \\
\hline & PoSS & 19 & 808.2 & 165.2 & 37.9 & 4.95 & $<0.001$ \\
\hline & Lt TS & & 552.4 & 176.0 & 40.4 & & \\
\hline & Difference & & 255.8 & 225.2 & 51.7 & & \\
\hline \multirow[t]{9}{*}{ Collagen fibers } & Poss & 20 & 0.4716 & 0.0786 & 0.0176 & -5.99 & $<0.001$ \\
\hline & SSS & & 0.6058 & 0.1039 & 0.0232 & & \\
\hline & Difference & & -0.1341 & 0.1001 & 0.0224 & & \\
\hline & Poss & 19 & 0.4674 & 0.0784 & 0.0180 & -4.90 & $<0.001$ \\
\hline & Rt TS & & 0.5555 & 0.0843 & 0.0193 & & \\
\hline & Difference & & -0.0881 & 0.0782 & 0.0180 & & \\
\hline & Poss & 17 & 0.4724 & 0.0755 & 0.0183 & -2.76 & 0.014 \\
\hline & Lt TS & & 0.5307 & 0.0931 & 0.0226 & & \\
\hline & Difference & & -0.0583 & 0.0871 & 0.0211 & & \\
\hline \multirow[t]{9}{*}{ Other tissues $\dagger$} & Poss & 21 & 0.03298 & 0.02004 & 0.00437 & 1.70 & 0.105 \\
\hline & SSS & & 0.02064 & 0.01690 & 0.00369 & & \\
\hline & Difference & & 0.01234 & 0.03333 & 0.00727 & & \\
\hline & PoSs & 20 & 0.03339 & 0.02048 & 0.00458 & 5.85 & $<0.001$ \\
\hline & Rt TS & & 0.00888 & 0.00612 & 0.00137 & & \\
\hline & Difference & & 0.02450 & 0.01872 & 0.00419 & & \\
\hline & PoSs & 19 & 0.03442 & 0.02050 & 0.00470 & 5.10 & $<0.001$ \\
\hline & Lt TS & & 0.00973 & 0.00613 & 0.00141 & & \\
\hline & Difference & & 0.02469 & 0.02109 & 0.00484 & & \\
\hline
\end{tabular}

* Some of the right TS, left TS, and SSS were absent or damaged during removal. Although the number of specimens available to be analyzed for this table was reduced, it didn't interfere with the overall result.

$\dagger$ Elastic fibers, connective tissue, blood vessels, and nerve fibers.

that they extended to the torcula and directed the venous blood flow toward the left TS and right TS rather than directly toward the CS. An example of this situation was found in Specimen 1, the posterior portion of which exhibited a septum adhering to the posterior wall of the CS. In these samples, wall dissection was influenced by the presence of septa. Spontaneous wall separation notwithstanding, two endothelium-lined lumens were observed in each specimen. The remainder of the wall, which was usually thinner, could not be delaminated. In the samples that exhibited vein-like structures within the SS (patent separation between the inferior wall layers notwithstanding), no endothelium was found between the two structures, which allowed us to extrapolate this information to possible surgical dissection of those layers.

Several structures were found within the internal walls of the dural venous sinuses; these included bands, bridges, tunnels, cusps, caves, and chords, often collectively known as chordae willisii. ${ }^{6}$ In the present study, the vacuolesalso known as caverns-were more relevant, because they seemingly facilitated delamination. Twelve SS portions exhibited vacuoles and were easy to delaminate, four portions exhibited vacuoles but were difficult to delaminate, and one portion could not be delaminated despite the presence of vacuoles. That fact notwithstanding, some of the lateral walls exhibited vacuoles but could not be delaminated.

The vacuoles in the SS walls, which are wrapped in collagen fibers, have been investigated by other authors and have been designated as cavernous spongy tissue. Balo analyzed 100 specimens and found that the density and localization of this tissue varied greatly. This author further suggested that variation in sinus wall volume and consequently in its lumen might play a role in regulation of the venous blood flow. After observing these caverns alternatively empty or filled with blood, he excluded the possibility that they were artifacts. ${ }^{3}$ Clark, in turn, was the first to describe formations in the dural floor of the SS, ${ }^{9}$ a feature that was later more thoroughly investigated by Dagain et al. and Balo, who did not believe that it regulated the brain venous blood flow but attributed that function to the cavernous tissue. ${ }^{3,11}$ Browder et al. found such 

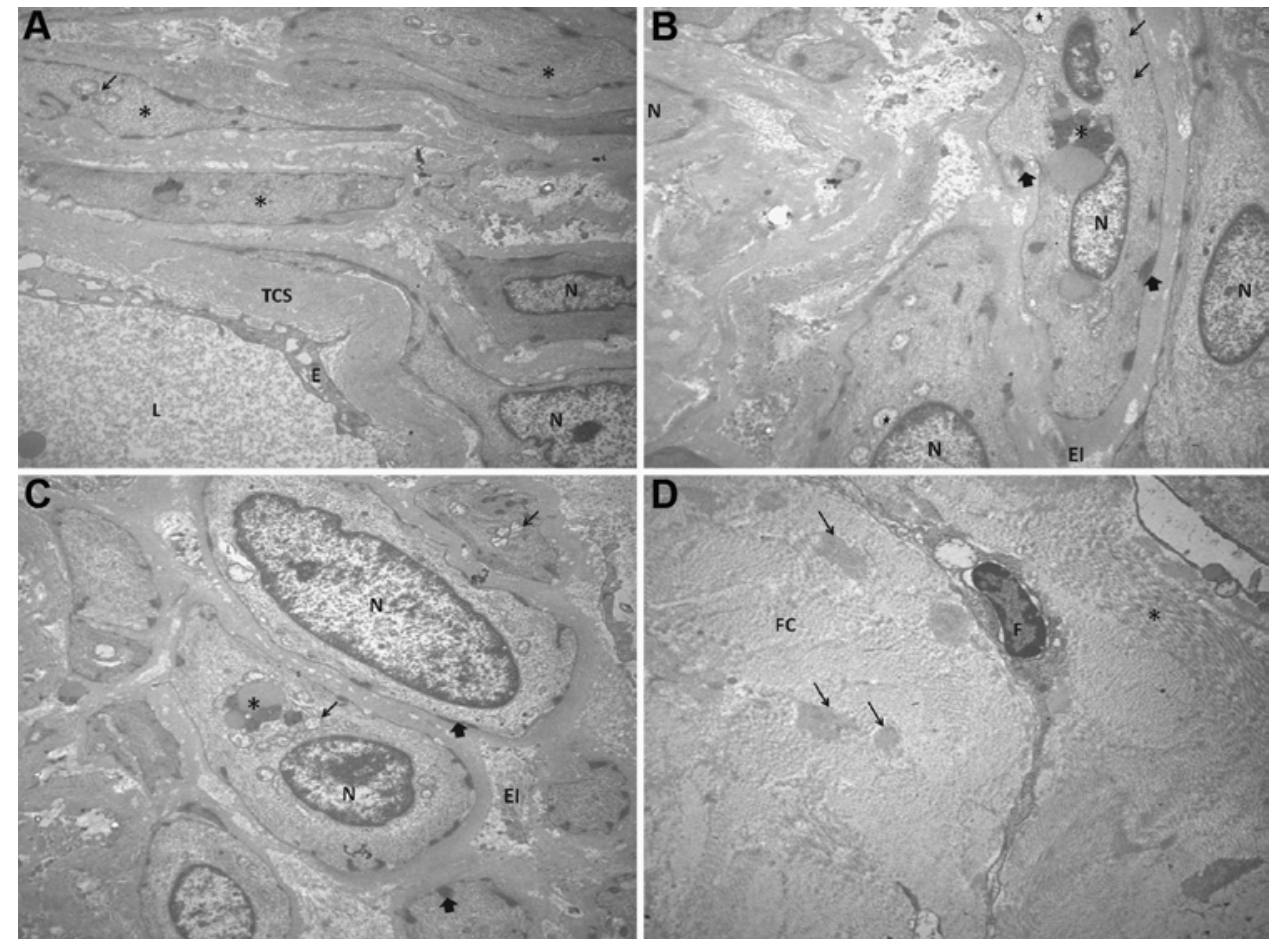

FIG. 6. A: Electron micrograph of the inferior wall of the MidSS beginning at its endothelium (E)-lined lumen (L). Note the presence of subendothelial connective tissue (TCS) with collagen, elastic, and some muscle (asterisk) fibers longitudinally arranged as part of the smooth-muscle layer, mitochondria in the sarcoplasm (arrow), and nuclei (N) of the smooth-muscle fibers. Original magnification $\times 6700$. B: Electron micrograph showing in detail some smooth-muscle fibers in the muscle layer of the inferior wall of the AnSS. Intercellular connective tissue (EI) with collagen fibers is present; the sarcolemma exhibits dense bodies all along its internal surface (wide arrows), and longitudinal fusiform dense areas (thin arrows) are present among the myofilaments, mitochondria (stars), glycogen and lipid particles (asterisk), and nuclei of the smooth-muscle fibers. Original magnification $\times 8000$. C: Electron micrograph showing in detail smooth-muscle fibers in the muscle layer of the inferior wall of the PoSS. Nuclei, mitochondria (thin arrows), and dense bodies are present all along the internal surface of the sarcolemma (wide arrows); the sarcoplasm of the central muscle fiber exhibits glycogen and lipid particles (asterisk), and intercellular connective tissue is present. Original magnification $\times 6700$. D: Electron micrograph of the external connective tissue layer of the inferior wall of the AnSS. Note the bundles of elastic fibers (arrows) with high electron density between the longitudinal (asterisk) and transverse collagen fibers (FC); at the center of the image one fibroblast $(F)$ with its nucleus and cytoplasm prolongations can be seen. Original magnification $\times 4000$.

cavernous tissue in $20 \%$ of 128 DM samples, but because they did not believe that it could vary, they considered it an embryonic tissue remnant. ${ }^{7}$ Dagain et al. did not find cavernous tissue in any of 25 analyzed specimens and suggested a possible role of this tissue in venous blood flow regulation, mediated by the contraction and relaxation of the junction between the VG and SS, based on the fact that they found smooth-muscle fibers, a large number of elastic fibers, and nerve structures in the SS floor in that area. ${ }^{11}$

\section{Association Between the Thickness and Composition of the DM and the Venous Sinuses in the Posterior Fossa}

Independent of the possibility of dissecting the SS wall, our results indicated that the inferior wall was thicker than the lateral walls in all of the SS portions. Application of these data to actual surgery might afford greater freedom in the dissection of neoplasms adhering to the DM in which the neoplasm is related to the inferior wall of the TC, even when it is related to the SS. However, in cases of supratentorial neoplasms adhering to the TC and falx cerebri, dissection of the lesion from the SS lateral walls should be undertaken with particular care because these walls are indisputably thinner and more fragile.
Ghali et al.'s anatomical-histological study showed that the SS wall is formed by dense fibrous tissue arranged in laminae of collagen bundles that run parallel to each other and are lined by vascular endothelium. They found an elevation projecting from the SS floor at the level of its junction with the VG that consisted of more or less interwoven bundles of collagen fibers that were again lined with vascular endothelium continuous with that of the SS..$^{15} \mathrm{In}$ contrast to the study of Ghali et al., which used longitudinal sections, ours was based on transverse sections of the SS and thus did not allow us to find that elevation. Nevertheless, the inferior wall was thicker than the lateral walls all along the SS extension (i.e., throughout its anterior, middle, and posterior portions). That finding might be explained by eventual prolongation of that elevation along the entire SS. In addition, all three portions of the SS were similar with respect to thickness and percentage of collagen and other tissues.

Dagain et al. showed that orcein staining targeting elastic fibers and immunohistochemical reactions for smoothmuscle actin and S100 protein in nerve fibers were positive in successive sections of the VG-SS junction. In the remainder of the SS, the number of smooth-muscle fibers 


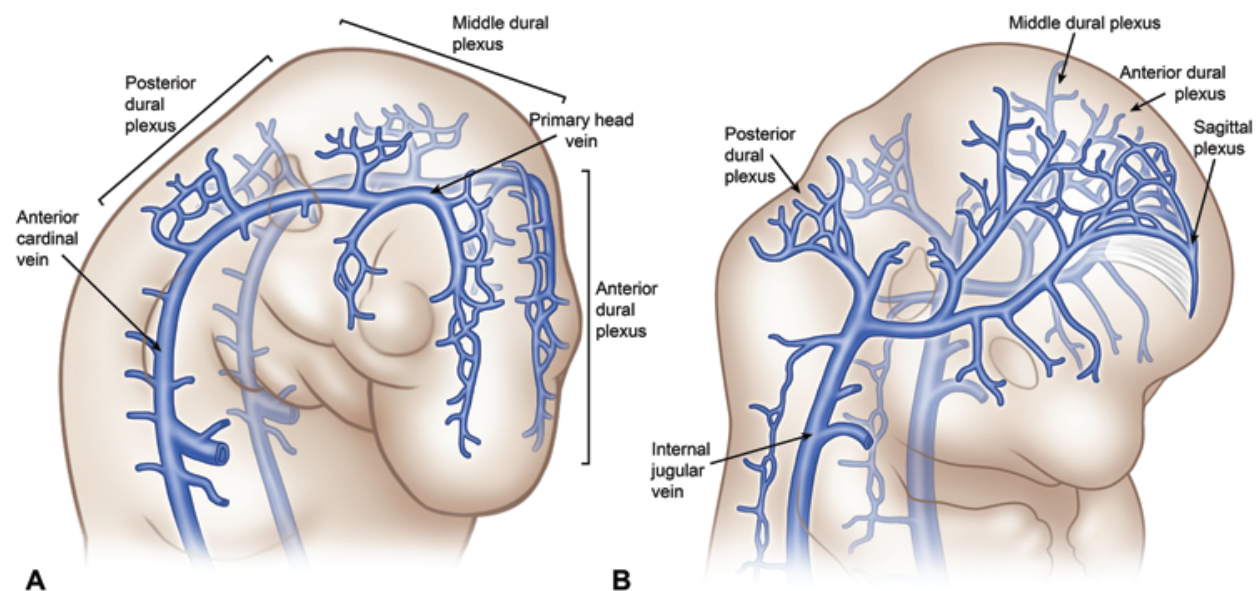

A

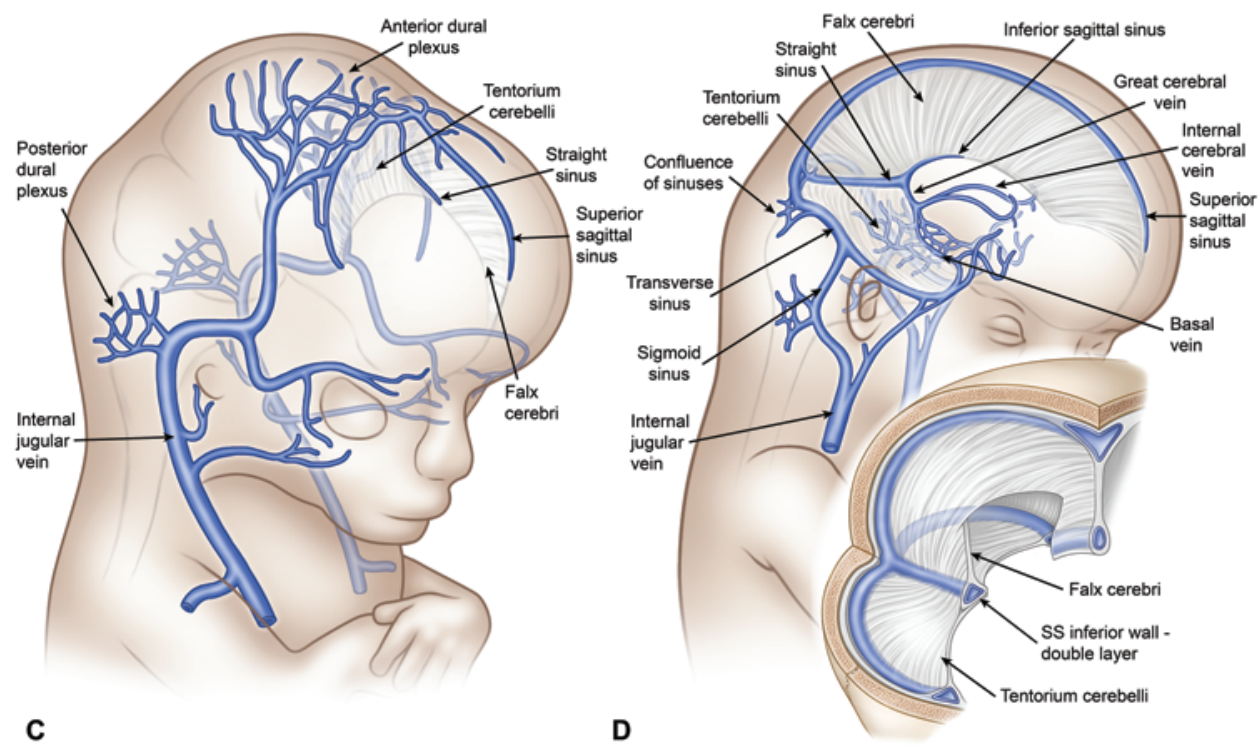

FIG. 7. Diagrams illustrating the development of the dural venous system. A: Primary arrangement consisting of the primary cephalic vein and the formation of the main dural plexuses (anterior, middle, and posterior) in a 5- to 10-mm embryo. B: Formation of the sagittal plexus from the anterior dural plexus as a function of the growth of the brain hemispheres in a 14- to 18-mm embryo. Note also the fusion of the anterior and middle plexuses and the changes in the labyrinth area. C: In this stage, the SSS can already be identified along the midline and the SS parallel to the falx cerebri in a 20 - to $35-\mathrm{mm}$ embryo. The middle plexus no longer exists. Changes continue at the optic capsule area and at the posterior plexus. D: The primitive TS is pushed backward by the sigmoid sinus and by the changes in the optic capsule, and both of the latter begin to develop their adult shapes in an 80-mm embryo. The TSs receive the tentorial sinuses, which are flattened due to brain growth. The internal cerebral vein begins to acquire its adult shape and becomes a tributary of the great cerebral vein instead of draining directly into the SS. The basal vein, which is formed from anastomoses between the primitive pial veins, first drains to the SS and later drains through the great cerebral vein. The SSS, TSs, and SS develop caudally; the CS represents the place at which that caudal development is complete. The CS has a plexiform appearance and is usually asymmetrical (according to Padget, Streeter, and Marin-Padilla24,27,34). The inset shows the falx cerebri, the TC, and the junction where the SS lies. A cut section of the SS illustrates the possible presence of dual dural layers at its inferior wall. Copyright Sara Jarret. Published with permission.

was higher in the sections closer to the junction with the VG. The staining for elastic fibers labeled the SS wall, while the SS floor tested positive for smooth-muscle actin and protein S100. Results of H \& E and S100 protein staining attested to the presence of nerve fibers in the SS floor. ${ }^{11}$ Vignes et al. had previously found smooth-muscle fibers in the venous-sinus junction of other sinuses, to which they attributed the function of a sphincter, with a role in the brain's venous hemodynamics. ${ }^{36}$ Dagain et al. further found that the number of elastic fibers in the SS lateral walls was greater in more anterior sections (i.e., closer to the vein-sinus junction). Our study did not find significant differences among the three portions of the SS floor in thickness or in percentage of collagen fibers or other tissues. However, the percentage of collagen fibers in the inferior wall was significantly lower than in the lateral walls in all three SS portions. That finding might be explained by the lower percentage of other tissues (elastic fibers, connective tissue, blood vessels, and nerve fibers) in the inferior wall of all three SS portions compared with their lateral walls.

The thickness of the SS posterior portion was greater 
than that of the right and left TS, but there were no differences between the PoSS and the SSS in this respect. In the study by Dagain et al., the authors found endothelial cells, some smooth-muscle fibers, and many nerve and elastic fibers in the SS-VG junction; thus, this area differed from the SSS and TSs, in which nerve and elastic fibers were rare..$^{11}$ Indeed, we found a greater percentage of other tissues, including elastic fibers, and consequently a lower percentage of collagen fibers, in the PoSS than in the SSS, left TS, and right TS; the only difference that was not statistically significant was the percentage of other tissues between the PoSS and SSS $(p=0.105)$.

\section{Findings on TEM Studies}

Regarding the composition of the SS wall as assessed by TEM, the presence of a layer consisting of fusiform smooth-muscle cells, occasionally exhibiting cytoplasmic extensions, stands out. That muscle layer, located deeper within the subendothelial connective tissue, was previously described only by Dagain et al.; the studies by Dobrovol'skii, Klika, and Ghali et al. did not report the presence of muscle fibers in the walls of the venous sinuses. ${ }^{11,13,15,20}$ Following a histological assessment, Balo concluded that there were no smooth-muscle fibers in the walls of the venous sinuses and that these fibers existed in the walls of dural arteries only. ${ }^{3}$ Vignes et al. described smooth-muscle fibers at the SSS vein-sinus junction. ${ }^{36}$

Ultrastructural analysis of the inferior wall of the SS performed using TEM did not reveal any histological differences among its three portions (anterior, middle, and posterior). These portions consisted of a thin endothelium, a thin layer of subendothelial connective tissue consisting of collagen and elastic fibers, and a deeper layer composed of smooth-muscle fibers. If the hypothesis that the venous blood flow is regulated by the VG-SS junction were true, as suggested by Dagain et al., the histological similarity among the three SS portions found in the present study would indicate that such properties might be present throughout the SS. The histological differences found by Dagain et al. between the VG-SS and other junctions might be due to embryological differences in the formation of the SS compared with the remainder of the sinuses; ${ }^{18,34}$ e.g., due to the fact that one of the walls of the SSS and TSs (uncovered sinuses) is formed by the periosteal layer of the DM. It is not clear whether that histological difference might play a role in the regulation of the brain's venous blood flow.

Although the DM is formed by dense collagen tissue and is highly inelastic, ${ }^{35}$ the presence of elastic fibers at a level deeper than the venous endothelium ${ }^{3}$ was confirmed by microscopic assessment using VIH staining. Despite the fact that the presence of muscle fibers was considered characteristic of the middle layers of veins and small veins, ${ }^{14}$ this was described in the SS wall only recently, ${ }^{11}$ and was confirmed by our ultrastructural assessment of the inferior wall of the SS. In some of the specimens, the macroscopic presence of two layers in the inferior wall of the SS gave the impression of a vein within a dural channel. Despite the strong support afforded by the joint presence of elastic and muscle fibers in that structure, the hypothesis of a real vein could not be confirmed in the present study, nor was it possible to confirm the functional theory concerning the regulation of the venous blood flow in the brain based on the putative contracting and relaxing properties of the SS walls, as some authors have suggested..$^{3,11}$ Nevertheless, the delamination of the inferior wall of the SS, as well as its double layering, which eventually is also macroscopically observable, suggest that resection of a part of the SS during surgical procedures without affecting its venous blood flow might be possible in some cases.

\section{Conclusions}

Ultrastructural assessment of the SS in 22 anatomical specimens led to the following conclusions.

1) The inferior wall of the SS was double layered and could be easily delaminated in most cases. It was thicker and had a lower percentage of collagen fibers and a higher percentage of other tissues, including elastic fibers, compared with the lateral walls in all three portions. In addition, ultrastructural analysis revealed the presence of muscle fibers in all three portions of the inferior wall of the SS.

2) There was no difference in thickness or percentage of collagen fibers and other tissues among the three portions of the SS.

3) The percentage of other tissues (elastic fibers, connective tissue, blood vessels, and nerve fibers) was higher, and consequently the percentage of collagen fibers was lower, in the posterior portion of the SS compared with the SSS and the right and left TS.

\section{Acknowledgments}

This study was supported by CAPES (Coordenação de Aperfeiçoamento de Pessoal de Nível Superior), a Brazilian research development agency. Marcelo Campos Moraes Amato received a monthly stipend of 1800 Brazilian reais in 2009 for his exclusive dedication to this study. We thank Professors José Alberto Landeiro, Marcius Benigno Marques dos Santos, Jair de Campos Soares, Luiza de Silva Lopes, and Mrs. Thaïs Cocarelli for their technical and publishing advice.

\section{References}

1. Andrews BT, Dujovny M, Mirchandani HG, Ausman JI: Microsurgical anatomy of the venous drainage into the superior sagittal sinus. Neurosurgery 24:514-520, 1989

2. Anson BJ, Maddock WG: Callander's Surgical Anatomy, ed 4. Philadelphia: Saunders, 1958

3. Balo J: The dural venous sinuses. Anat Rec 106:319-324, 1950

4. Bisaria KK: Anatomic variations of venous sinuses in the region of the torcular Herophili. J Neurosurg 62:90-95, 1985

5. Bonnal J, Brotchi J: Surgery of the superior sagittal sinus in parasagittal meningiomas. J Neurosurg 48:935-945, 1978

6. Browder J, Browder A, Kaplan HA: The venous sinuses of the cerebral dura mater. I. Anatomical structures within the superior sagittal sinus. Arch Neurol 26:175-180, 1972

7. Browder J, Kaplan HA, Krieger AJ: Anatomical features of the straight sinus and its tributaries. J Neurosurg 44:55-61, 1976

8. Castellano F, Ruggiero G: Meningiomas of the posterior fossa. Acta Radiol Suppl 104:1-177, 1953

9. Clark WE: A vascular mechanism related to the great vein of Galen. BMJ 1:476, 1940

10. Colli BO, Carlotti CG Jr, Assirati JA Jr, Dos Santos MB, Neder L, Dos Santos AC: Parasagittal meningiomas: followup review. Surg Neurol 66 (Suppl 3):S20-S28, 2006 
11. Dagain A, Vignes JR, Dulou R, Dutertre G, Delmas JM, Guerin J, et al: Junction between the great cerebral vein and the straight sinus: an anatomical, immunohistochemical, and ultrastructural study on 25 human brain cadaveric dissections. Clin Anat 21:389-397, 2008

12. DiMeco F, Li KW, Casali C, Ciceri E, Giombini S, Filippini $\mathrm{G}$, et al: Meningiomas invading the superior sagittal sinus: surgical experience in 108 cases. Neurosurgery 55:12631274,2004

13. Dobrovol'skii GF: Ultrastructure of the meninges. Neurosci Behav Physiol 14:100-110, 1984

14. Gartner LP, Hiatt JL: Tratado de Histologia em Cores, ed 3. Rio de Janeiro: Elsevier, 2007

15. Ghali WM, Rafla MF, Ekladious EY, Ibrahim KA: A study of the junction between the straight sinus and the great cerebral vein. J Anat 164:49-54, 1989

16. Hammock MK, Milhorat TH, Earle K, Di Chiro G: Vein of Galen ligation in the primate. Angiographic, gross, and light microscopic evaluation. J Neurosurg 34:77-83, 1971

17. Houdart E, Saint-Maurice JP, Boissonnet H, Bonnin P: Clinical and hemodynamic responses to balloon test occlusion of the straight sinus: technical case report. Neurosurgery 51:254-257, 2002

18. Kaplan HA, Browder J: Neurosurgical consideration of some features of the cerebral dural sinuses and their tributaries. Clin Neurosurg 23:155-169, 1976

19. Kaplan HA, Browder J, Knightly JJ, Rush BF Jr, Browder A: Variations of the cerebral dural sinuses at the torcular Herophili. Importance in radical neck dissection. Am J Surg 124:456-461, 1972

20. Klika E: The ultrastructure of meninges in vertebrates. Acta Univ Carol [Med] (Praha) 13:53-71, 1967

21. Machado ABM: Neuroanatomia Funcional, ed 2. São Paulo: Atheneu, 2002

22. Mağden AO: Triple straight sinus-report of 2 cases. Anat Anz 173:17-22, 1991

23. Marin-Padilla M: Early vascularization of the embryonic cerebral cortex: Golgi and electron microscopic studies. J Comp Neurol 241:237-249, 1985

24. Marin-Padilla M: Embryogenesis of the early vascularization of the central nervous system, in Yaşargil MG (ed): Microneurosurgery. Clinical Considerations and Microsurgery of Arteriovenous Racemous Angiomas. Stuttgart: Thieme, 1987, pp 23-47

25. Matsushima T, Suzuki SO, Fukui M, Rhoton AL Jr, de Oliveira E, Ono M: Microsurgical anatomy of the tentorial sinuses. J Neurosurg 71:923-928, 1989

26. Muthukumar N, Palaniappan P: Tentorial venous sinuses: an anatomic study. Neurosurgery 42:363-371, 1998

27. Padget DH: The cranial venous system in man in reference to development, adult configuration, and relation to the arteries. Am J Anat 98:307-355, 1956

28. Park HK, Bae HG, Choi SK, Chang JC, Cho SJ, Byun BJ, et al: Morphological study of sinus flow in the confluence of sinuses. Clin Anat 21:294-300, 2008
29. Rhoton AL Jr: The posterior fossa veins. Neurosurgery $\mathbf{4 7}$ (3 Suppl):S69-S92, 2000

30. Ryu CW: Persistent falcine sinus: is it really rare? AJNR Am J Neuroradiol 31:367-369, 2010

31. Saxena RC, Beg MA, Das AC: Double straight sinus. Report of six cases. J Neurosurg 39:540-542, 1973

32. Saxena RC, Beg MA, Das AC: The straight sinus. J Neurosurg 41:724-727, 1974

33. Singh M, Nagashima M, Inoue Y: Anatomical variations of occipital bone impressions for dural venous sinuses around the torcular Herophili, with special reference to the consideration of clinical significance. Surg Radiol Anat 26:480-487, 2004

34. Streeter GL: The development of the dural sinuses of the dura mater in the human embryo. Am J Anat 18:145-178, 1915

35. Testut L, Jacob O: Cavité cranienne et son contenu, in Traité D’Anatomie Topographique. Paris: Octave Doin, 1929, pp 83-91

36. Vignes JR, Dagain A, Guérin J, Liguoro D: A hypothesis of cerebral venous system regulation based on a study of the junction between the cortical bridging veins and the superior sagittal sinus. Laboratory investigation. J Neurosurg 107:1205-1210, 2007

\section{Disclosures}

The authors report no conflict of interest concerning the materials or methods used in this study or the findings specified in this paper.

\section{Supplemental Information \\ Previous Presentations}

This study was presented at the XV WFNS World Congress of Neurosurgery in Seoul, Korea, in 2013. It was also presented as a thesis by Marcelo Campos Moraes Amato to the analyzing committee of the University of São Paulo for doctoral degree approval.

\section{Author Contributions}

Conception and design: Amato, Tirapelli, Colli. Acquisition of data: Amato. Analysis and interpretation of data: Amato. Drafting the article: Amato. Critically revising the article: Tirapelli, Colli. Reviewed submitted version of manuscript: Colli. Approved the final version of the manuscript on behalf of all authors: Amato. Statistical analysis: Amato. Administrative/technical/material support: all authors. Study supervision: Colli.

\section{Correspondence}

Marcelo Campos Moraes Amato, Av. Brasil, 2283 São Paulo, São Paulo, CEP 01431-001, Brazil. email: amato@neurocirurgia. com. 